\title{
Postoperative Analgesic Efficacy of Erector Spinae Plane Block in Patients Undergoing Lumbar Spinal Surgery: A Systematic Review and Meta-Analysis
}

\author{
Min-jun Liu $\cdot$ Xu-yan Zhou $\cdot$ Yi-bing Yao $\cdot$ Xu Shen · Rong Wang • \\ Qi-hong Shen (D)
}

Received: February 4, 2021 / Accepted: March 12, 2021 / Published online: April 7, 2021

(C) The Author(s) 2021

\begin{abstract}
Lumbar spine surgery is one of the most widespread types of surgery for treating back and leg pain. However, the postoperative period always presents with severe pain due to the removal of skin, subcutaneous tissues, bones, and ligaments. Patients usually require high doses of opioids to relieve pain during the initial three days after operation, as well as experience drugrelated complications and prolonged length of stay in hospital. We found that Erector spinae plane block significantly reduced postoperative opioid consumption and pain scores. The present systematic review revealed that ESPB was effective and safe for postoperative analgesia.
\end{abstract}

Keywords: Erector spinae plane block; Lumbar spinal surgery; Meta-analysis

\section{Liu}

Department of Anesthesiology and Department of Nursing Education, Sir Run Run Shaw Hospital, School of Medicine, Zhejiang University, 3 Qingchun Road East, Jianggan District, Hangzhou 310016, Zhejiang, People's Republic of China

X. Zhou · Y. Yao · X. Shen · R. Wang · Q. Shen ( $ه)$ Department of Anesthesiology, Affiliated Hospital of Jiaxing University, Jiaxing, Zhejiang, China e-mail: shenqihong1989@163.com

\section{Key Summary Points}

Why carry out this study?

Patients usually require high doses of opioids to relieve pain after lumbar spine surgery, and experienced various drugrelated complications.

Erector spinae plane block (ESPB) is a novel regional block technique that has been reported as effective for relieving postoperative pain, but no systematic and persuasive evidence has been presented.

We conducted a systematic review and meta-analysis to explore the safety and efficacy of ESPB in lumbar spine surgery.

\section{What was learned from the study?}

This study showed that ESPB reduced opioid consumption and provided effective analgesia during the first 24 postoperative hours.

ESPB effectively improves postoperative analgesia in patients undergoing lumbar spine surgery. 


\section{DIGITAL FEATURES}

This article is published with digital features, including a summary slide, to facilitate understanding of the article. To view digital features for this article go to https://doi.org/10.6084/ m9.figshare.14199329.

\section{INTRODUCTION}

Lumbar spine surgery is one of the most widespread types of surgery for treating back and leg pain. However, the postoperative period always presents severe pain due to the removal of skin, subcutaneous tissues, bones, and ligaments. Patients usually require high doses of opioids to relieve pain during the initial 3 days after operation, and also experience drug-related complications and prolonged length of hospital stay [1]. In addition, severe postoperative pain can lead to delayed out-of-bed activity, deep venous thrombosis, postoperative delirium, and chronic pain syndrome [2]. Unlike other types of surgeries, such as thoracic and abdominal surgery, lumbar spinal surgery lacks an effective regional block technique to reduce the consumption of opioids used to relieve postoperative pain. Therefore, it is essential to find a safe and effective way of relieving postoperative pain associated with lumbar spinal surgery.

Erector spinae plane block (ESPB) is a novel regional block technique, which was first described by Forero in 2016 as the injection of local anesthetic into the plane between the deep fascia of the erector spinae muscle and the vertebral transverse process under ultrasound guidance [3]. Over the last few years, ESPB has been demonstrated to be effective in various type of surgeries, including breast surgery [4], thoracic surgery [5], and laparoscopic cholecystectomy [6], among others. Several randomized controlled trials (RCTs) have reported that ESPB could be a factor influencing postoperative analgesia after lumbar spinal surgery [7, 8]; however, no systematic and persuasive evidence has been presented.

Therefore, we conducted a systematic review and meta-analysis of RCTs to explore the safety and efficacy of ESPB in lumbar spine surgery.

\section{METHODS}

The present systematic review and meta-analysis was conducted according to the Preferred Reporting Items for Systematic Reviews and Meta Analyses (PRISMA) guidelines. This article is based on previously conducted studies and does not contain any new studies with human participants or animals performed by any of the authors.

\section{Systematic Literature Search}

PubMed, Embase, the Cochrane Library, and Web of Science databases were independently searched by two researchers to identify RCTs available since the establishment of the databases to January 31, 2021. No restrictions were placed on language. The search strategy for the PubMed database was as follows: ESPB [All Fields] OR (erector [All Fields] AND ("spine" [MeSH Terms] OR "spine"[All Fields]) AND plane block [All Fields])), OR erector spinae plane block [All Fields]. In addition, we manually searched for the references of included studies to determine whether there were potential related trials.

\section{Selection Criteria and Data Extraction}

Studies that satisfied the selection criteria were included, and the inclusion criteria were as follows: (1) studies with patients undergoing lumbar spine surgery; (2) studies with interventions that clearly described single ESPB as an auxiliary analgesia technique (timing, location, concentration, and dose of local anesthetic) after administration of general anesthesia; (3) studies involving comparisons such as no intervention or sham block; (4) studies with postoperative opioid consumption as an outcome; and (5) studies designed as RCTs. The exclusion criteria were as follows: (1) ongoing clinical trials; (2) trials on animals or cadaver research; (3) continuous ESPB; and (4) duplicate publications.

We used EndNote X9 to exclude duplicate trials. Two authors scanned the titles and abstracts of the articles to establish whether 
they were eligible. Subsequently, the full text of the articles was carefully assessed to examine whether they satisfied the inclusion criteria. Differences of opinion were settled by a third author. The data from eligible studies were extracted and cross-checked independently by two authors. Data extracted included the name of the first author, age, year of publication, number of participants, the American Society of Anesthesiologists scale, ESPB technique, general anesthesia technique, patient-controlled intravenous analgesia (PCIA), and outcomes. In the case of incomplete data, the reviewers attempted to contact the authors of the original articles via email to request additional and complete data.

\section{Quality and Risk Assessment}

We evaluated the risk of bias in studies included in the systematic review using Cochrane Review Manager (Version 5.3; The Nordic Cochrane Centre, The Cochrane Collaboration, Copenhagen, Denmark, 2014). The criteria used were as follows: random sequence generation, allocation concealment, double-blinding, blinding of outcome assessment, incomplete outcome data, selective reporting, and other biases. Each trial was assessed independently by two reviewers and classified as low risk, unclear risk, or high risk.

The quality of evidence was assessed using the Grading of Recommendations Assessment, Development, and Evaluation (GRADE) system for outcomes based on the following criteria: study design, risk of bias, rating inconsistency in results, rating of indirectness of evidence, and others. The quality of evidence was divided into four levels: high, moderate, low, and very low. Funnel plots were used to evaluate publication bias.

\section{Primary and Secondary Outcomes}

Consumption of opioids during the first 24 postoperative hours was the primary outcome. Opioids required by patients that served as rescue analgesia after surgery and the use of a patient-controlled analgesia device constituted opioid consumption. The secondary outcomes were postoperative pain scores at different time points, the number of patients requiring rescue analgesia, and the occurrence of adverse events. Pain scores used included the visual analogue and numerical rating scales. We included active pain scores for trials that evaluated pain scores at different states in the present study.

\section{Statistical Analysis}

The meta-analysis was conducted using Review Manager (version 5.3; The Nordic Cochrane Centre, The Cochrane Collaboration, Copenhagen, Denmark, 2014). A pooled risk ratio (RR) and $95 \%$ confidence intervals (CIs) were calculated for dichotomous outcomes. A $P$ value of $<0.05$ was considered statistically significant. Mean difference (MD) and 95\% CI were calculated for continuous data using the same units. Otherwise, a standardized mean difference (SMD) was applied. Continuous data described in statistics as median (range) were converted to means and standard deviations according to a previously described method $[9,10]$. Heterogeneity of trials was assessed using the $I^{2}$ statistic. High heterogeneity was likely to be observed due to clinical and methodological factors; therefore, a random effects model was applied in the present metaanalysis despite a low $I^{2}$ value.

\section{RESULTS}

\section{Search Results}

A total of 2103 relevant studies were obtained from the databases after conducting an initial search. Subsequently, we excluded 886 duplicated studies and 1205 studies with irrelevant abstracts and titles. We carefully evaluated the remaining 12 studies by reading the full text to determine whether they were eligible. Six studies were further excluded for the following reasons: studies were reviews and case reports $(n=2)$ [11, 12], retrospective study $(n=1)$ [13], compared ESPB with other types of regional blocks $(n=2)[14,15]$, and an ongoing trial 
$(n=1)$ [16]. Finally, six studies [8, 17-21] satisfied the inclusion criteria and were used for the meta-analysis. The literature screening process is illustrated in Fig. 1.

\section{Study Characteristics}

Six RCTs with 360 patients (180 patients in the ESPB group and 180 patients in the control group with no intervention or sham intervention) were considered in the present metaanalysis. The publication years of the eligible studies ranged from 2019 to 2021. ESPB was performed between T10 and L3. Four studies $[8,19-21]$ used bupivacaine as a local anesthetic, while two studies used ropivacaine. The concentration of the local anesthetics ranged from 0.025 to $0.5 \%$. PCIA was used to relieve postoperative pain in five trials $[8,17,18,20,21]$. Detailed information regarding studies included in the meta-analysis is presented in Table 1.

\section{Risk of Bias}

Four studies $[8,17,19,21]$ explicitly reported the method of random sequence generation, and three studies $[17,18,20]$ described allocation concealment. None of the studies described the blinding of participants and personnel. All studies mentioned that the assessors were blinded and attrition bias was evaluated. No selective reporting was observed. All studies calculated the sample sizes, and the other bias was classified as "low risk". A summary of the risk of bias is presented in Fig. 2 .

\section{Outcomes}

All studies reported opioid consumption during the first 24 postoperative hours. Synthesized results revealed that patients who received ESPB had a significantly lower opioid requirements after surgery than patients in the control group $(\mathrm{SMD}=-3.82,95 \% \mathrm{CI}[-5.70,-1.94] ; P<0.01$, $I^{2}=97 \%$, Fig. 3).

Postoperative pain scores were assessed at six different time points: $2 \mathrm{~h}, 4 \mathrm{~h}, 6 \mathrm{~h}, 8 \mathrm{~h}, 12 \mathrm{~h}$, and $24 \mathrm{~h}$ after surgery. Forest plots revealed that
ESPB reduced postoperative pain scores significantly $(2 \mathrm{~h}: \quad \mathrm{MD}=-1.89, \quad 95 \%$ CI $[-2.64$, $-1.14] ; \quad P<0.01, I^{2}=87 \% ; 4 \mathrm{~h}: \mathrm{MD}=-1.46$, 95\% CI $[-2.45,-0.47] ; P<0.01, I^{2}=92 \% ; 6 \mathrm{~h}$ : $\mathrm{MD}=-2.15,95 \%$ CI $[-2.60,-1.70] ; P<0.01$, $I^{2}=0 \% ; 8 \mathrm{~h}: \quad \mathrm{MD}=-1.64,95 \%$ CI $[-2.26$, $-1.01] ; P<0.01, I^{2}=87 \% ; 12 \mathrm{~h}: \mathrm{MD}=-1.09$, $95 \%$ CI $[-1.71,-0.47] ; P<0.01, I^{2}=81 \% ; 24$ h: $\mathrm{MD}=-0.68,95 \%$ CI $[-0.88,-0.49] ; P<0.01$, $I^{2}=0 \%$, Fig. 4).

Four studies recorded the numbers of patients who required rescue analgesia. A forest plot revealed that ESPB reduced the number of patients requiring rescue analgesia significantly $(\mathrm{RR}=0.36, \quad 95 \% \quad \mathrm{CI} \quad[0.24-0.54], \quad P<0.01$, $I^{2}=33 \%$, Fig. 5).

Five studies recorded the incidence of postoperative nausea and vomiting. A forest plot revealed that the incidence of postoperative nausea and vomiting were considerably lower in the ESPB group than in the control group (RR 0.25, 95\% CI 0.14-0.47, $P<0.01, I^{2}=0 \%$, Fig. 6). Two studies recorded the incidence of itching, and a forest plot revealed no significant difference between the ESPB and control groups (RR 0.63, 95\% CI 0.06-6.68, $P=0.70, I^{2}=76 \%$, Fig. 7). No ESPB operation-related complications such as local anesthetic toxicity, bleeding, neuraxial injury, or infection were reported in the included studies.

\section{Publication Bias}

We did not evaluate publication bias because the number of eligible studies was small [22].

\section{Grade Assessment}

All included studies were randomized trials. All the assessors were blinded, there was no selective reporting and the other bias, the "risk of bias" was graded as "not serious"; $I^{2}>30 \%$, which indicated "inconsistency", was graded as "serious". Three trials $[17,19,21]$ reported opioid consumption and pain scores as median (interquartile range) or median (min-max), which indicated "indirectness" was classified as "serious". The overall results of GRADE are presented in Table 2. 


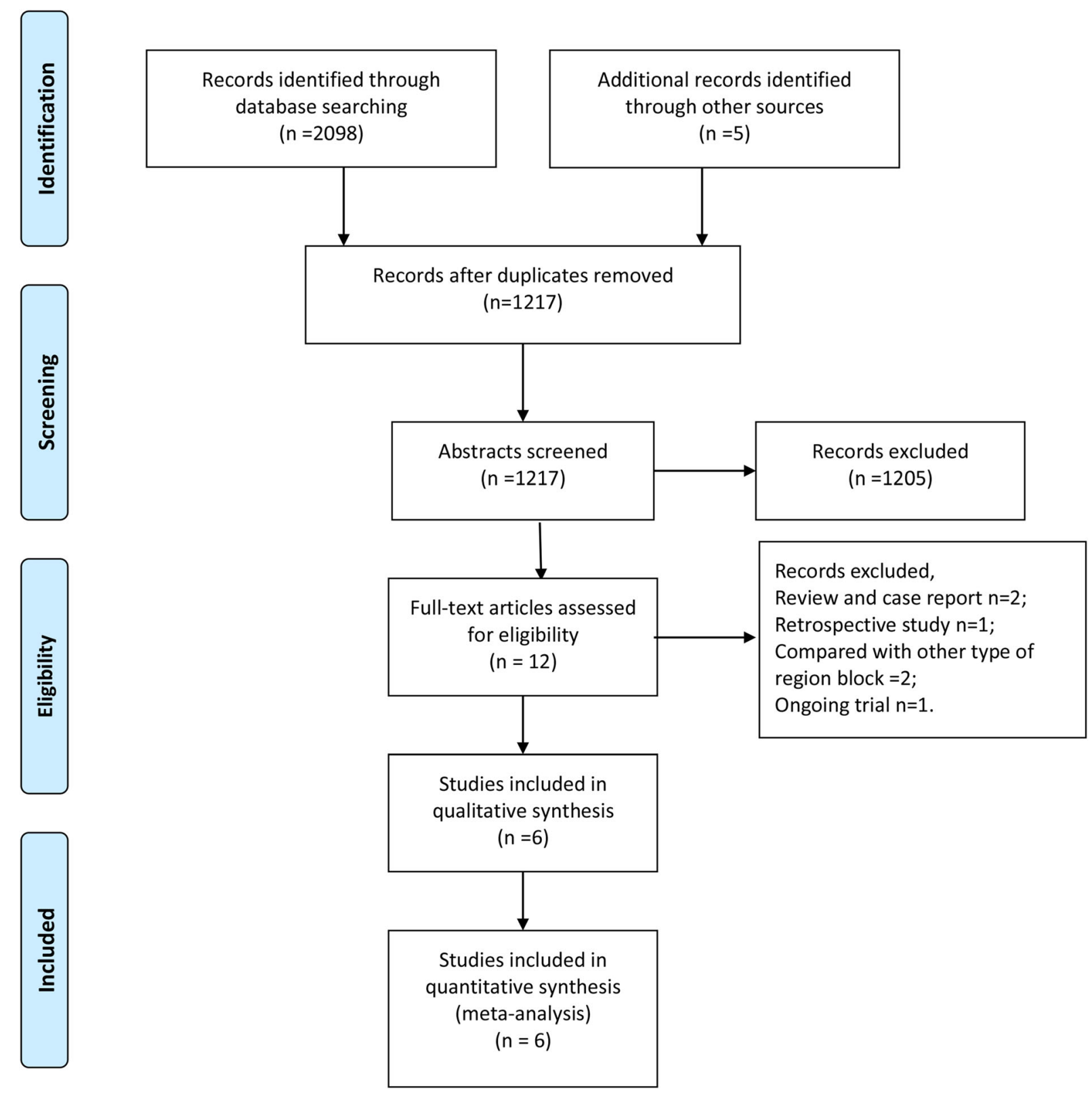

Fig. 1 Flow chart of study retrieval

\section{DISCUSSION}

To the best of our knowledge, this was the first meta-analysis conducted on RCTs to evaluate the efficacy of single ESPB in patients undergoing lumbar spinal surgery. The results of the comprehensive analyses revealed that ESPB significantly reduced opioid consumption and relieved postoperative pain; the quality of evidence was rated as low and moderate.

The mechanism of action of ESPB remains unclear. Forero et al. [3] demonstrated that local anesthetics could block the ventral and dorsal rami of the spinal nerve roots and produce an extensive sensory block. A previous cadaveric study revealed that anesthetics spread to the epidural, paravertebral, and intercostal spaces, in turn generating an effective blocking effect 


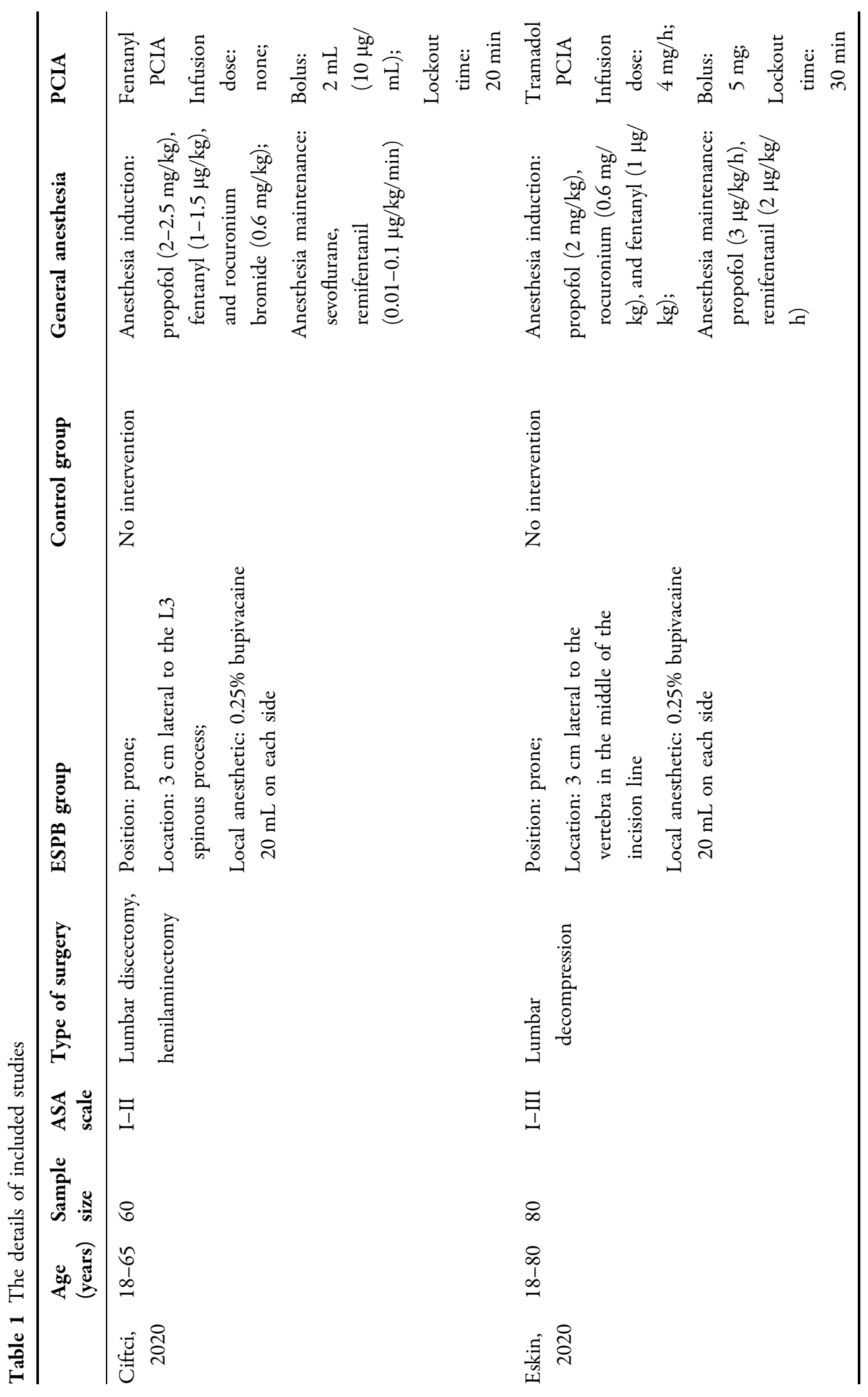




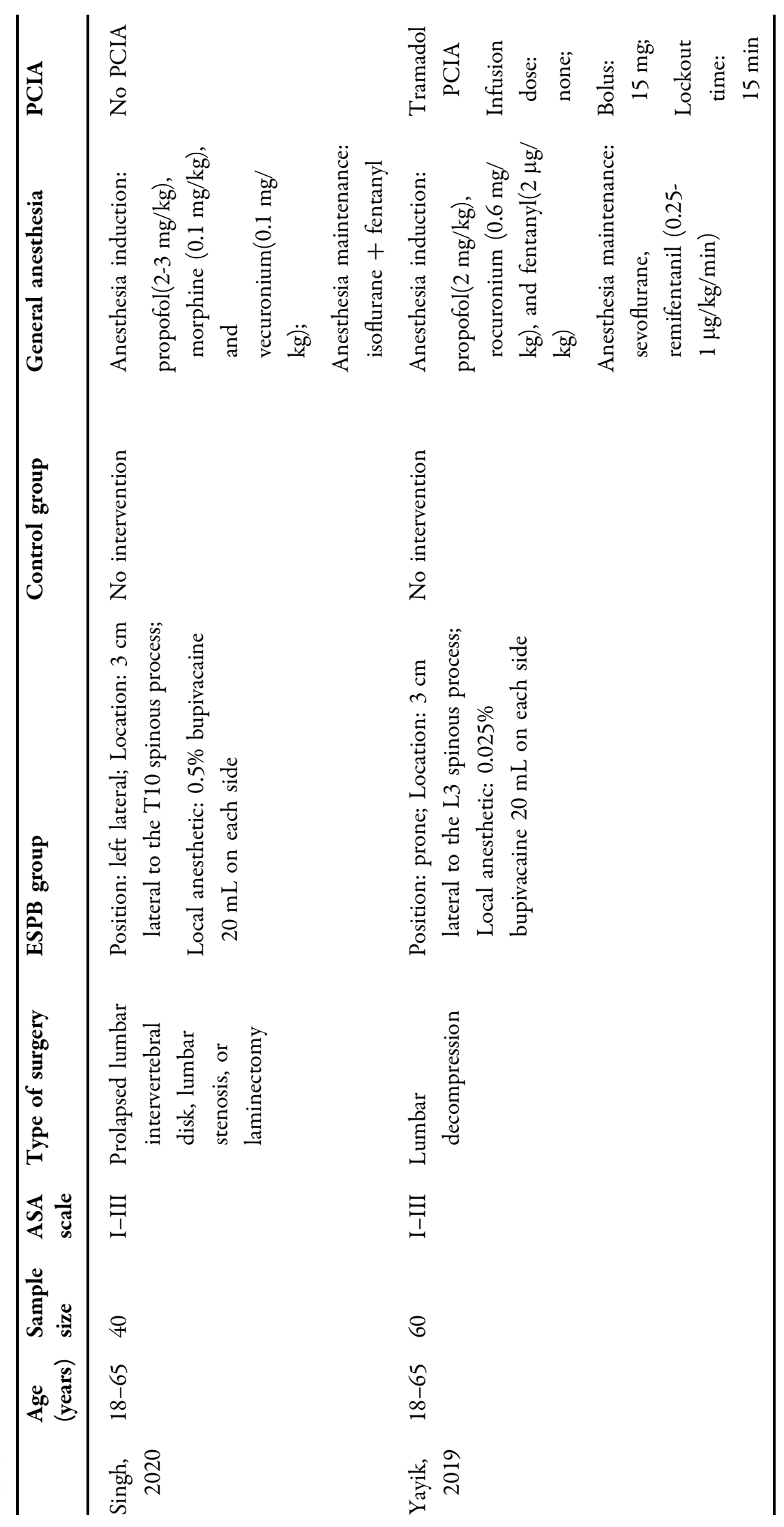




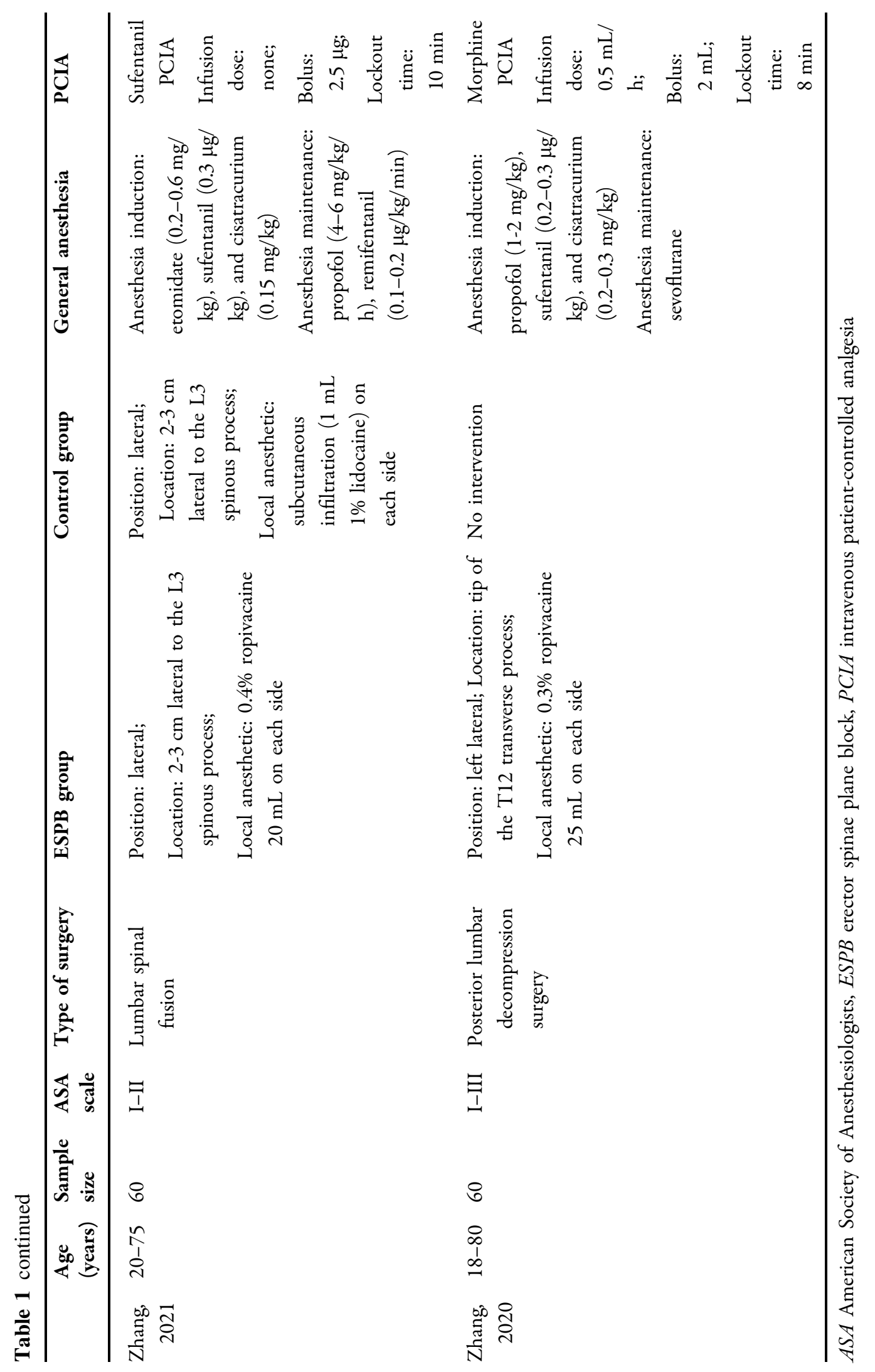




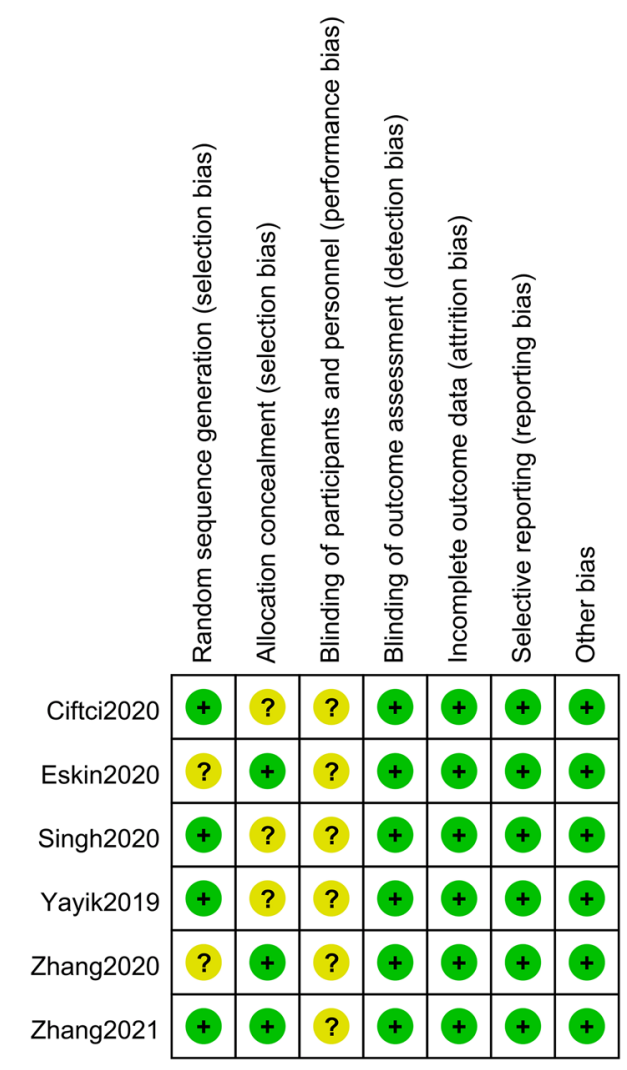

Fig. 2 Risk of bias of included studies

[23]. However, a recent cadaver study revealed that local anesthetics did not spread to the dorsal anterior branch in most cases [24]. Despite the uncertain mechanism of action, ESPB has been widely used as postoperative analgesic over the last few years, and it seems to have achieved satisfactory results [25-27]. A previous meta-analysis [28] demonstrated that ESPB is an effective strategy to improve postsurgical analgesia. However, as the authors mentioned, various surgical procedures with anatomical differences resulted in significant heterogeneity in the study.

Posterior lumbar spine surgery is one of the most painful surgical procedures [29]. Studies have revealed that opioid-based intravenous patient-controlled analgesia is most frequently used to overcome pain after spinal decompression surgery [30]. However, patients could suffer the side effects of opioid use ranging from relatively mild disorders, such as nausea, vomiting, and hypotension, to severe side effects such as loss of consciousness and respiratory depression. Additionally, as traditional regional anesthesia techniques of epidural anesthesia, paravertebral blocks are associated with risks including inadvertent motor blockade, deep vein thrombosis, hypotension, urinary retention, pneumothorax, vascular puncture, and epidural hematoma [31]. Therefore, ESPB can potentially serve as a safe and effective method for regional analgesia.

Our meta-analysis revealed that postoperative pain score and opioid consumption decreased significantly in patients who underwent ESPB, which demonstrated its effectiveness. As an important part of enhanced recovery after surgery (ERSA), effectively relief of postoperative pain is a problem that needs to be solved. Further, ESPB does not interfere with respiratory functioning, which meets the requirements of ERSA [32]. Furthermore, the occurrence of postoperative nausea and vomiting was significantly reduced compared with the control group. This may be a benefit from the decreased consumption of opioids during the postoperative period.

There are currently few documented operation-related complications of ultrasound-guided

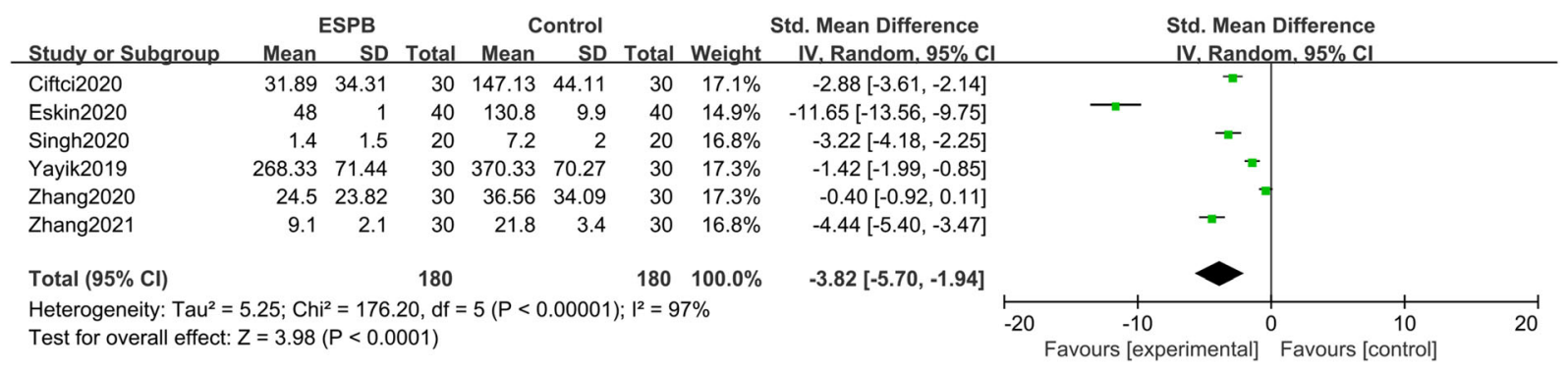

Fig. 3 Forest plot of pooled analysis showing the postoperative opioid consumption 


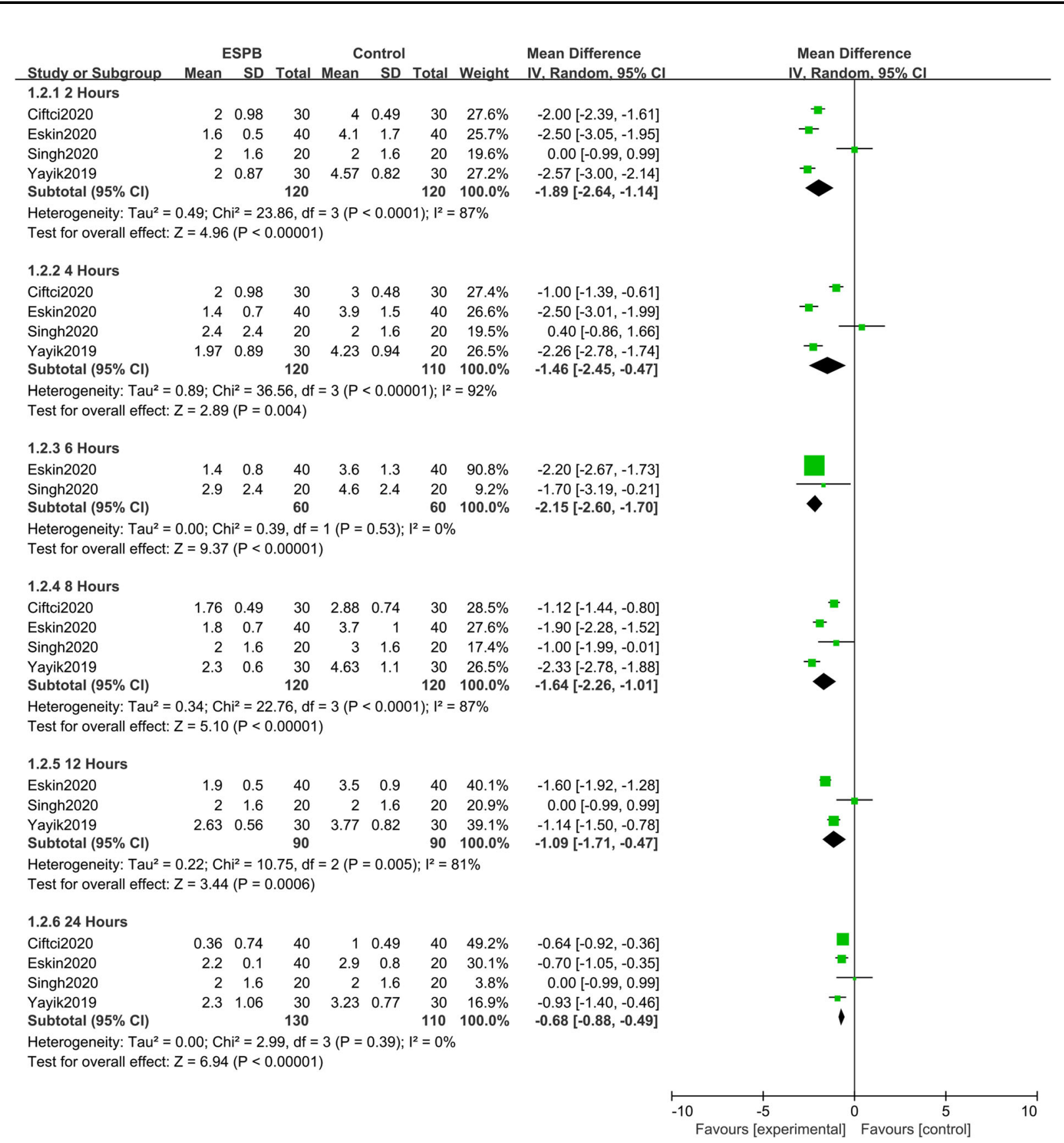

Fig. 4 Forest plot of pooled analysis showing the pain score at different time points during postoperative period

ESPB in the literature. Ueshima [33] described the first report of iatrogenic pneumothorax following ESPB, and OSelvi et al. [34] first reported motor weakness related to the ESPB in a 29-year-old patient after a cesarean section delivery. No ESPB operation-related complications were observed in our selected studies. Notably, high-quality studies with large sample sizes have demonstrated that the safety of ESPB is essential.

The majority of quality of evidence in the present systematic review was graded as low and moderate, which could be attributed to the following: First, most of the outcomes were continuous data and the studies had high heterogeneity. Second, opioid consumption 


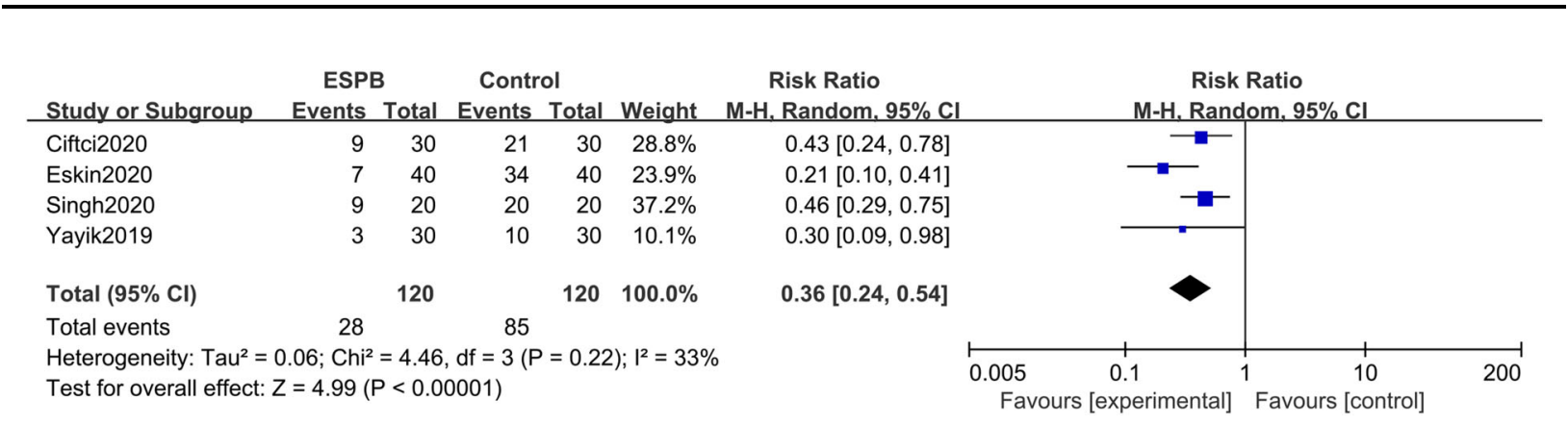

Fig. 5 Forest plot of pooled analysis showing the incidence of requiring rescue analgesia

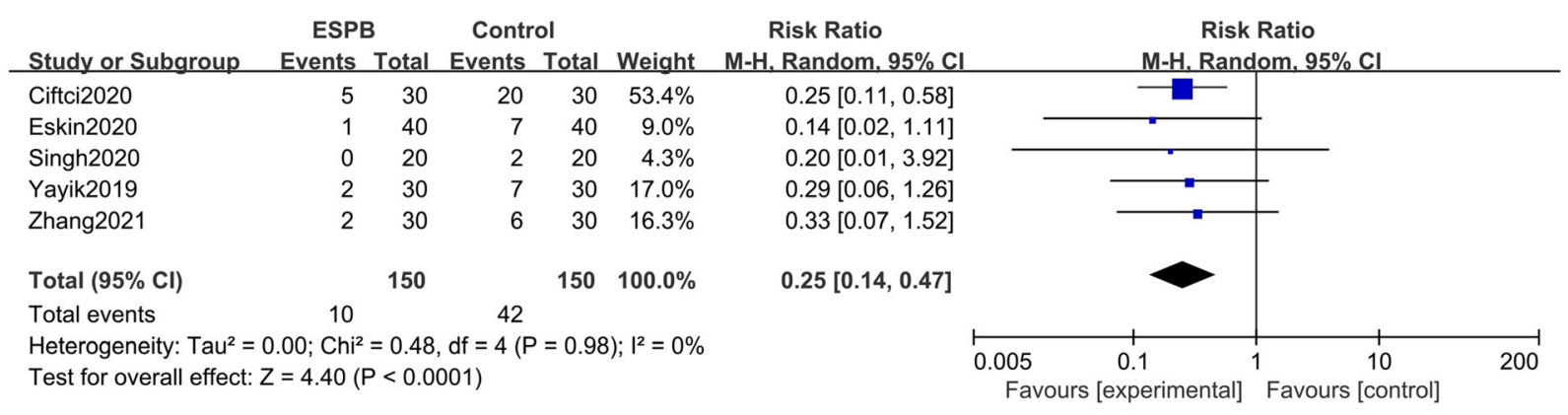

Fig. 6 Forest plot of pooled analysis showing the incidence of postoperative nausea and vomiting

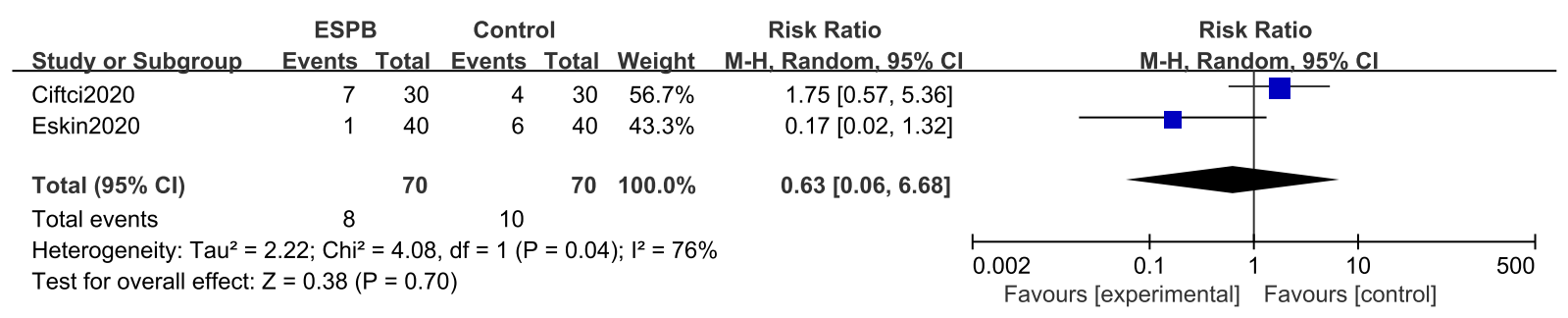

Fig. 7 Forest plot of pooled analysis showing the incidence of itching

and pain scores were not normally distributed, and had to be transformed into means and standard deviations, which suggests that the evidence was indirect. Third, the application of double-blinding in the included studies was a challenge because no intervention or sham block was lacking in the control group. Furthermore, clinical heterogeneity could have existed because of the various general anesthetic drugs and different ESPB techniques used. Consequently, we adopted a random effects model for the meta-analysis.

\section{Limitations}

The present systematic review had certain limitations. First, the sample size of eligible studies was relatively small; therefore, further studies should be conducted with larger sample sizes. Second, the majority of trials did not report on double-blinding and allocation concealment; however, the assessors were blinded. Third, the databases we searched are not of equal quality. Fourth, we did not compare ESPB with other types of blocks because there were no RCTs relevant to the subject; therefore, we could not determine the advantages and disadvantages of 
Table 2 The overall results of GRADE evaluation

\begin{tabular}{|c|c|c|c|c|}
\hline Outcome & $\begin{array}{l}\text { MD/SMD/RR } \\
(95 \% \mathrm{CI})\end{array}$ & $I^{2}$ & $\begin{array}{l}\text { Quality of } \\
\text { evidence }\end{array}$ & Reasons \\
\hline Opioid consumption & $\begin{array}{l}-3.82(-5.70 \\
-1.94)\end{array}$ & $97 \%$ & $\begin{array}{l}\oplus \oplus \bigcirc \bigcirc \\
\text { LOW }\end{array}$ & $\begin{array}{l}\text { Indirectness was "serious"; Inconsistency was } \\
\text { "serious" }\end{array}$ \\
\hline $\begin{array}{l}\text { Pain score at } 2 \mathrm{~h} \\
\text { postoperatively }\end{array}$ & $1.89(-2.64,-1.14)$ & $87 \%$ & $\begin{array}{l}\oplus \oplus \bigcirc \bigcirc \\
\text { LOW }\end{array}$ & $\begin{array}{l}\text { Indirectness was "serious"; Inconsistency was } \\
\text { "serious" }\end{array}$ \\
\hline $\begin{array}{l}\text { Pain score at } 4 \mathrm{~h} \\
\text { postoperatively }\end{array}$ & $\begin{array}{l}-1.46(-2.45 \\
-0.47)\end{array}$ & $92 \%$ & $\begin{array}{l}\oplus \oplus \bigcirc \bigcirc \\
\text { LOW }\end{array}$ & $\begin{array}{l}\text { Indirectness was "serious"; Inconsistency was } \\
\text { "serious" } \\
\text { "serious" serious" }\end{array}$ \\
\hline $\begin{array}{l}\text { Pain score at } 6 \mathrm{~h} \\
\text { postoperatively }\end{array}$ & $\begin{array}{l}-2.15(-2.60 \\
-1.70)\end{array}$ & $0 \%$ & $\begin{array}{l}\oplus \oplus \oplus \bigcirc \\
\text { MODERATE }\end{array}$ & Indirectness was "serious" \\
\hline $\begin{array}{l}\text { Pain score at } 8 \mathrm{~h} \\
\text { postoperatively }\end{array}$ & $\begin{array}{l}-1.64(-2.26 \\
-1.01)\end{array}$ & $87 \%$ & $\begin{array}{l}\oplus \oplus \bigcirc \bigcirc \\
\text { LOW }\end{array}$ & $\begin{array}{l}\text { Indirectness was "serious"; Inconsistency was } \\
\text { "serious" }\end{array}$ \\
\hline $\begin{array}{l}\text { Pain score at } 12 \mathrm{~h} \\
\text { postoperatively }\end{array}$ & $\begin{array}{l}-1.09(-1.71 \\
-0.47)\end{array}$ & $81 \%$ & $\begin{array}{l}\oplus \oplus \bigcirc \bigcirc \\
\text { LOW }\end{array}$ & $\begin{array}{l}\text { Indirectness was "serious"; Inconsistency was } \\
\text { "serious" }\end{array}$ \\
\hline $\begin{array}{l}\text { Pain score at } 24 \mathrm{~h} \\
\text { postoperatively }\end{array}$ & $\begin{array}{l}-0.68(-0.88 \\
-0.49)\end{array}$ & $0 \%$ & $\begin{array}{l}\oplus \oplus \oplus \bigcirc \\
\text { MODERATE }\end{array}$ & Indirectness was "serious" \\
\hline $\begin{array}{l}\text { Incidence of rescue } \\
\text { analgesia }\end{array}$ & $0.36(0.24,0.54)$ & $33 \%$ & $\begin{array}{l}\oplus \oplus \oplus \bigcirc \\
\text { MODERATE }\end{array}$ & Inconsistency was "serious" \\
\hline Incidence of PONV & $0.25(0.14,0.47)$ & $0 \%$ & $\begin{array}{l}\oplus \oplus \oplus \oplus \\
\mathrm{HIGH}\end{array}$ & None \\
\hline Incidence of itching & $0.63(0.06,6.68)$ & $76 \%$ & $\begin{array}{l}\oplus \oplus \oplus \bigcirc \\
\text { MODERATE }\end{array}$ & Inconsistency was "serious" \\
\hline
\end{tabular}

$\bar{b}$ hour, $M D$, mean difference, $S M D$ standardized mean difference, $R R$ risk ratio, $E S P B$ erector spinae plane block, $P O N V$ postoperative nausea vomiting

ESPB when compared with other types of blocks after lumbar spinal surgery.

\section{CONCLUSION}

Overall, ESPB can serve as an effective and safe postoperative analgesia after lumbar spinal surgery. Nevertheless, future studies should be conducted to validate our findings and to compare ESPB with different types of regional block analgesia, in addition to focusing on postoperative quality of recovery.

\section{ACKNOWLEDGEMENTS}

Funding. This study was supported by grants from Jiaxing Key Discipline of Medicine-Anesthesiology (2019-zc-06) and Medical and Health 
Science and Technology Program of Zhejiang Province (2021KY742). The journal's Rapid Service Fee was funded by the authors.

Authorship. All named authors meet the International Committee of Medical Journal Editors (ICMJE) criteria for authorship for this article, take responsibility for the integrity of the work as a whole, and have given their approval for this version to be published.

Authorship Contributions. Min-jun Liu and Qi-hong Shen: conceptualization and methodology. Xu-yan Zhou, Yi-bing Yao and Xu Shen: data curation and formal analysis. Rong Wang: project administration and supervision. Minjun Liu and Qi-hong Shen: software, writingoriginal draft, and writing-review and editing. All authors contributed to the article and approved the submitted version.

Disclosures. Min-jun Liu, Xu-yan Zhou, Yibing Yao, Xu Shen, Rong Wang, and Qi-hong Shen have nothing to disclose.

Compliance with Ethics Guidelines. This article is based on previously conducted studies and does not contain any new studies with human participants or animals performed by any of the authors.

Data Availability. All data relevant to the study are included in the article or uploaded as supplementary information.

Open Access. This article is licensed under a Creative Commons Attribution-NonCommercial 4.0 International License, which permits any non-commercial use, sharing, adaptation, distribution and reproduction in any medium or format, as long as you give appropriate credit to the original author(s) and the source, provide a link to the Creative Commons licence, and indicate if changes were made. The images or other third party material in this article are included in the article's Creative Commons licence, unless indicated otherwise in a credit line to the material. If material is not included in the article's Creative Commons licence and your intended use is not permitted by statutory regulation or exceeds the permitted use, you will need to obtain permission directly from the copyright holder. To view a copy of this licence, visit http://creativecommons.org/licenses/by$\mathrm{nc} / 4.0 /$.

\section{REFERENCES}

1. Andreae MH, Andreae DA. Regional anaesthesia to prevent chronic pain after surgery: a cochrane systematic review and meta-analysis. Br J Anaesth. 2013;111:711-20.

2. Tan M, Law LS, Gan TJ. Optimizing pain management to facilitate enhanced recovery after surgery pathways. Can J Anaesthesia. 2015;62:203-18.

3. Forero M, Adhikary SD, Lopez H, Tsui C, Chin KJ. The erector spinae plane block: a novel analgesic technique in thoracic neuropathic pain. Reg Anesth Pain Med. 2016;41:621-7.

4. Leong RW, Tan ESJ, Wong SN, Tan KH, Liu CW. Efficacy of erector spinae plane block for analgesia in breast surgery: a systematic review and metaanalysis. Anaesthesia. 2020.

5. Zhao H, Xin L, Feng Y. The effect of preoperative erector spinae plane vs. paravertebral blocks on patient-controlled oxycodone consumption after video-assisted thoracic surgery: a prospective randomized, blinded, non-inferiority study. J Clin Anesthesia 2020.

6. Koo CH, Hwang JY, Shin HJ, Ryu JH. The Effects of Erector Spinae Plane Block in Terms of Postoperative Analgesia in Patients Undergoing Laparoscopic Cholecystectomy: A Meta-Analysis of Randomized Controlled Trials. J Clin Med 2020;9.

7. Zhang Q, Wu Y, Ren F, Zhang X, Feng Y. Bilateral ultrasound-guided erector spinae plane block in patients undergoing lumbar spinal fusion: a randomized controlled trial. J Clin Anesthesia 2021.

8. Yayik AM, Cesur S, Ozturk F, Ahiskalioglu A, Ay AN, Celik EC, et al. Postoperative analgesic efficacy of the ultrasound-guided erector spinae plane block in patients undergoing lumbar spinal decompression surgery: a randomized controlled study. World Neurosurg. 2019;126:e779-85.

9. Luo D, Wan X, Liu J, Tong T. Optimally estimating the sample mean from the sample size, median, mid-range, and/or mid-quartile range. Stat Methods Med Res. 2018;27:1785-805. 
10. Wan X, Wang W, Liu J, Tong T. Estimating the sample mean and standard deviation from the sample size, median, range and/or interquartile range. BMC Med Res Methodol. 2014;14:135.

11. Qiu Y, Zhang T-J, Hua Z. Erector spinae plane block for lumbar spinal surgery: a systematic review. J Pain Res. 2020;13:1611-9.

12. Schwartz R, Urits I, Viswanath O, Kaye AD, Eskander J. Use of erector spinae plane block for perioperative pain control in a patient undergoing spinal surgery. Cureus. 2020;12:e9646.

13. Owen RJ, Brodke DS, Quinlan N, Lawrence BD, Spiker WR, Poduska A, et al. Preoperative regional erector spinae plane blocks reduce opioid use, increase mobilization, and reduce length of stay following lumbar spine fusion. Spine J. 2020;20: S21.

14. Siam EM, Abo Aliaa DM, Elmedany S, Abdelaa ME. Erector spinae plane block combined with general anaesthesia versus conventional general anaesthesia in lumbar spine surgery. Egypt J Anaesthesia. 2020;36:201-26.

15. Schwartz RH, Urits I, Viswanath O, Urman RD, Kaye AD, Eskander JP (2020) Successful combination of thoracodorsal interfascial plane block and erector spinae pain block for peri-operative pain control after lumbar laminectomy. J Clin Anesthesia. 62.

16. Eskin M, Ceylan A, Ozhan M, Atik B (2020) Ultrasound-guided erector spinae block versus midtransverse process to pleura block for postoperative analgesia in lumbar spinal surgery. Der Anaesthesist.

17. Zhang Q, Wu Y, Ren F, Zhang X, Feng Y. Bilateral ultrasound-guided erector spinae plane block in patients undergoing lumbar spinal fusion: a randomized controlled trial. J Clin Anesth. 2021;68: 110090.

18. Zhang TJ, Zhang JJ, Qu ZY, Zhang HY, Qiu Y, Hua Z. Bilateral erector spinae plane blocks for open posterior lumbar surgery. J Pain Res. 2020;13:709-17.

19. Singh S, Choudhary NK, Lalin D, Verma VK. Bilateral ultrasound-guided erector spinae plane block for postoperative analgesia in lumbar spine surgery: a randomized control trial. J Neurosurg Anesthesiol. 2020;32:330-4.

20. Eskin MB, Ceylan A, Özhan MÖ, Atik B. Ultrasound-guided erector spinae block versus midtransverse process to pleura block for postoperative analgesia in lumbar spinal surgery. Anaesthesist. 2020;69:742-50.
21. Ciftci B, Ekinci M, Celik EC, Yayik AM, Aydin ME, Ahiskalioglu A. Ultrasound-guided erector spinae plane block versus modified-thoracolumbar interfascial plane block for lumbar discectomy surgery: a randomized. Controlled Study World Neurosurg. 2020;144:e849-55.

22. Sterne JA, Sutton AJ, Ioannidis JP, Terrin N, Jones DR, Lau J, et al. Recommendations for examining and interpreting funnel plot asymmetry in metaanalyses of randomised controlled trials. BMJ (Clin Res Ed). 2011;343:d4002.

23. Schwartzmann A, Peng P, Maciel MA, Forero M. Mechanism of the erector spinae plane block: insights from a magnetic resonance imaging study. Can J Anaesthesia. 2018;65:1165-6.

24. Ivanusic J, Konishi Y, Barrington MJ. A Cadaveric study investigating the mechanism of action of erector spinae blockade. Reg Anesth Pain Med. 2018;43:567-71.

25. Kamel AAF, Amin OAI, Ibrahem MAM. Bilateral ultrasound-guided erector spinae plane block versus transversus abdominis plane block on postoperative analgesia after total abdominal hysterectomy. Pain Physician. 2020;23:375-82.

26. $\mathrm{Xu} \mathrm{L}$, Leng JC, Elsharkawy H, Hunter OO, Harrison TK, Vokach-Brodsky L, et al. Replacement of fascia iliaca catheters with continuous erector spinae plane blocks within a clinical pathway facilitates early ambulation after total hip arthroplasty. Pain Med. 2020;21:2423-9.

27. Mostafa SF, Abdelghany MS, Abdelraheem TM, Abu Elyazed MM. Ultrasound-guided erector spinae plane block for postoperative analgesia in pediatric patients undergoing splenectomy: a prospective randomized controlled trial. Paediatr Anaesth. 2019;29:1201-7.

28. Kendall MC, Alves L, Traill LL, De Oliveira GS. The effect of ultrasound-guided erector spinae plane block on postsurgical pain: a meta-analysis of randomized controlled trials. BMC Anesthesiol. 2020;20:99.

29. Gerbershagen HJ, Aduckathil S, van Wijck AJ, Peelen LM, Kalkman CJ, Meissner W. Pain intensity on the first day after surgery: a prospective cohort study comparing 179 surgical procedures. Anesthesiology. 2013;118:934-44.

30. Bohl DD, Louie PK, Shah N, Mayo BC, Ahn J, Kim TD, et al. (2016) Multimodal versus patient-controlled analgesia after an anterior cervical decompression and fusion. Spine (Phila Pa 1976). 41: 994-8. 
31. Gottschalk A, Freitag M, Tank S, Burmeister MA, Kreil S, Kothe R, et al. Quality of postoperative pain using an intraoperatively placed epidural catheter after major lumbar spinal surgery. Anesthesiology. 2004;101:175-80.

32. Sultan P, Sultan E, Carvalho B. Regional anaesthesia for labour, operative vaginal delivery and caesarean delivery: a narrative review. Anaesthesia. 2021;76(Suppl 1):136-47.
33. Ueshima H. Pneumothorax after the erector spinae plane block. J Clin Anesth. 2018;48:12.

34. Selvi O, Tulgar S. Ultrasound guided erector spinae plane block as a cause of unintended motor block. Rev Esp Anestesiol Reanim. 2018;65:589-92. 